\title{
Do Relief Pitching and Remaining Games Create Moral Hazard Problems in
}

\section{Major League Baseball?}

Kevin Baldini

Mark T. Gillis

Matt E. Ryan 


\title{
Do Relief Pitching and Remaining Games Create Moral Hazard Problems in Major League Baseball?
}

\begin{abstract}
Previous research neglects to consider additional sources of moral hazard in baseball beyond the designated hitter rule. Using a game-level analysis similar to Bradbury and Drinen (2006), we find that an additional National League relief pitcher leads to more hit batsmen than an additional American League relief pitcher and that the number of games remaining in the National League has a smaller positive effect on the number of hit batsmen than the number of games remaining in the American League, though the latter relationship is economically small. Both results, however, imply additional avenues by which moral hazard emerges.
\end{abstract}

JEL classifications: D81, L83

Keywords: Moral Hazard, Baseball, Relief Pitching, Games Remaining, Designated Hitter, Retaliation 


\section{Introduction}

Major League Baseball (MLB) provides an exceptional natural experiment to test the theory of moral hazard. Due to the presence of the designated hitter $(\mathrm{DH})$ rule $^{1}$ in the American League (AL) but not in the National League (NL), AL pitchers are insured against the costs of increasingly reckless behavior - namely, since they do not bat, AL pitchers incur lower costs of hitting opposing batters, because they cannot be retaliated against. The result is a difference in hit batsmen across leagues due to the discrepancy in playing rules.

Previous research confirms this outcome. In the first analysis of moral hazard within MLB, Goff, Shughart and Tollison (1997) find that batters in the AL are hit at rates $10 \%$ to $15 \%$ higher than those in the NL. Bradbury and Drinen $(2006 ; 2007)$ confirm the moral hazard hypothesis, and Kawaura and Croix (2007) find evidence in Japanese professional league, where a similar discrepancy in rules creates the same moral hazard scenario.

[Figure 1 about here.]

However, certain studies have called into question the existence of such an effect. Levitt (1998) shows that pitchers are hit extremely infrequently and, should retaliation be the sole motive for a pitcher being hit by pitch, pitchers received such a punishment only one out of every fifty times they hit an opposing batter. Trandel, White, and Klein (1998) and Trandel (2004) find no evidence of the moral hazard effect on pitchers. Kawaura (2010) shows that pitchers in Japanese leagues who experienced the implementation of the designated hitter rule in the middle of their careers did not take advantage of the increased protection from retaliation. Further, since the moral hazard argument rests on rule differences between the two leagues, the AL should consistently witness more hit batsmen by virtue of the fact that their pitchers do not bat. Figure 1 
shows that while a separation in hit batsmen rates seemed to exist at the onset of the DH rule in 1973, the difference seems to have dissipated more recently.

In this analysis, we look to identify alternative sources of moral hazard by pitchers within the game of baseball, utilizing game-level data and a model most similar to that used by Bradbury and Drinen (2006). We focus on two potential areas. First, can the increased reliance upon relief pitching — that is, pitchers used for short periods after the starting pitcher has left the game — create a situation of moral hazard? Recall that the moral hazard hypothesis for pitchers arises from the fact that some pitchers - those in the AL— do not bat, and thus the cost/benefit calculation for their actions changes. While relief pitchers in the AL do not bat due to the DH rule, relief pitchers in the NL rarely bat as well. Relief pitchers are poor offensive players and managers generally have the ability to utilize combinations of player substitutions to avoid having a relief pitcher bat. Therefore, while a relief pitcher in the NL could bat according to the rules, in actuality, relief pitchers rarely $d o$ bat. $^{2}$ We would expect, then, that NL relief pitchers would face a moral hazard problem due to the fact that they do not bat. Furthermore, as the incidence of relief pitching rises, we would expect NL pitchers to behave more like AL pitchers. Our results show that the number of hit batsmen rises as the number of relief pitchers in a game increases and also that this increase is larger in the NL than in the AL, lending support to the hypothesis that relief pitching could be a significant source of moral hazard for pitchers.

To our knowledge, only Stephenson (2004) has considered the role of relief pitchers as separate from starting pitchers. He hypothesizes that if a starting pitcher switches leagues to the NL (AL), his behavior should adjust and he should hit fewer (more) batters due to the absence (presence) of the DH rule and the moral hazard it creates. However, since relief pitchers do not 
bat, this behavior shift should not occur in relief pitchers. Stephenson (2004), though, finds no evidence to support the moral hazard hypothesis.

Second, does the number of games remaining against a particular team create a moral hazard dilemma? Consider the cost to a NL pitcher of hitting a batter at the beginning of a season and at the end of a season. Since the potential for retaliation is greater when there are more games left in the season, a moral hazard would seem to develop as the season progresses and fewer games remain against any one particular opponent. ${ }^{3}$ However, since this effect would occur only when pitchers can bat, only NL pitchers would be subject to this particular form of moral hazard. Our results show that although there is an unexpected positive relationship between the number of games remaining and the number of batters hit in a game, the relationship is actually smaller in the NL than in the AL, which is consistent with moral hazard. However, the size of the difference in this case is very small.

The paper will proceed as follows. Section II outlines the empirical methodology and data. Section III describes the results. Section IV concludes.

\section{Data \& Methodology}

The data used in this paper is from Retrosheet, Inc. and Sports Reference, LLC and consists of all regular season MLB games from 1973 to $2008 .^{4}$ No playoff games are included. As in Bradbury and Drinen (2006), the year 1973 is chosen as the starting point because it is the first year in which the DH was utilized.

Following Bradbury and Drinen (2006), a Poisson regression is used to model the number of hit batsmen for a team in each game, since the dependent variable is a positive count outcome 
with generally low numbers. Equation (1) represents the Poisson regression used to model hit batsmen in a game in this paper.

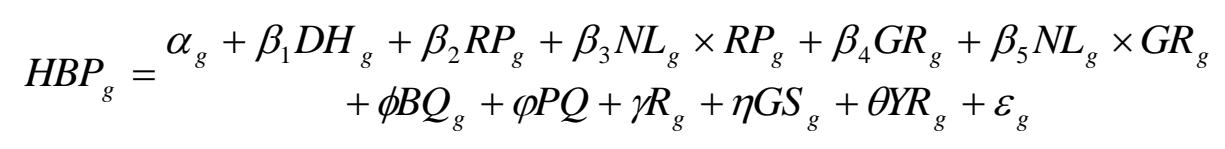

The dependent variable and most of the independent variables used here are the same as those used in Bradbury and Drinen (2006). The dependent variable $H B P_{g}$ is the number of Hit Batsmen on the batting team in game $g$. The independent variable $\mathrm{DH}_{g}$ is a dummy variable equal to 1 whenever game $g$ is played with the DH rule. The vectors $B Q_{g}, P Q_{g}, R_{g}, G S_{g}$, and $Y R_{g}$ are comprised of control variables. The vector $B Q_{g}$ represents a vector of batter quality variables including Runs Scored per Game. The quality of the opposing team's batters is important to consider as a factor in the number of hit batsmen per game; ceteris paribus, better offensive teams have more at bats per game, and thus more opportunities to incur hit batsmen. The vector $P Q_{g}$ represents a vector of pitcher quality variables including Runs Allowed per Game and Walks Allowed per Game. The quality of the pitcher plays a direct role in determining the number of hit batsmen per game, particularly pitchers with inferior control. The vector $R_{g}$ represents a vector of retaliation variables including Batters Hit and Home Runs. Anecdotal evidence shows that pitchers hit batters to retaliate on behalf of previously hit teammates as well as for home runs hit by opponents. The vector $G S_{g}$ represents a vector of game-specific variables including Runs Ahead and/or Behind and Absolute Score. Particular game circumstances may play a role in the incidence of hit batsmen; ceteris paribus, the cost of a hit batsman to the defensive team is higher in closer games, and games with higher score have more at-bats and, therefore, more chances to incur hit batsmen. The vector $Y R_{g}$ represents a vector of 
year dummies. The batter quality, pitcher quality, retaliation, game-specific, and year variables are the same as those used in Bradbury and Drinen (2006), and direct the reader to that study for a more detailed discussion.

The major difference in this paper compared to past literature is that it takes into account other possible moral hazard problems in MLB, in particular by also accounting for relief pitching and the number of games remaining. This is done by including three additional variables, $R P_{g}$, $G R_{g}$, and $N L_{g}$. The variable $R P_{g}$ represents the number of Relief Pitchers used in a game by the pitching team. The variable $G R_{g}$ represents the number of Games Remaining in that season between the two teams playing in that game. The variable $N L_{g}$ is a dummy variable equal to 1 if the game is being played under NL rules, such that the pitcher bats, and equal to 0 if the game is being played under AL rules, such that the pitcher does not bat. ${ }^{5}$ The variable $N L$ is only used in interaction with Relief Pitchers and Games Remaining.

Recall, the moral hazard hypothesis suggests that the effect of an additional relief pitcher in the NL is larger than the effect of an additional relief pitcher in the AL, as an NL reliever is expected to behave more like an AL pitcher since he rarely bats and therefore rarely faces retaliation. Correspondingly, an additional NL reliever is expected to increase the number of hit batsmen more than an additional AL reliever. ${ }^{6}$ Furthermore, the moral hazard hypothesis predicts that the effect of a game remaining in the NL would be smaller than in the AL because NL pitchers are concerned not only about the threat of retaliation in the present game, but also in a future game. Since AL pitchers bat in neither present nor future games, this future threat is also non-existent in the AL.

Notice, equation (2) represents the regression equation when the game is being played under NL rules, such that $N L$ is equal to 0 and $D H$ is equal to 1 : 


$$
H B P_{g}=\alpha_{g}+\left(\beta_{2}+\beta_{3}\right) R P_{g}+\left(\beta_{4}+\beta_{5}\right) G R_{g}+\phi B Q_{g}+\varphi P Q+\gamma R_{g}+\eta G S_{g}+\theta Y R_{g}+\varepsilon_{g} .
$$

Similarly, equation (3) represents the regression equation when the game is being played under $A L$ rules, such that $N L$ is equal to 0 and $D H$ is equal to 1 :

$$
H B P_{g}=\alpha_{g}+\beta_{1}+\beta_{2} R P_{g}+\beta_{4} G R_{g}+\phi B Q_{g}+\varphi P Q+\gamma R_{g}+\eta G S_{g}+\theta Y R_{g}+\varepsilon_{g} .
$$

The difference between the coefficient on $R P_{g}$ in equation (2) versus (3) is $\beta_{3}$, which represents the additional effect of a relief pitcher in the NL on the number of hit batsmen. ${ }^{7}$ So, if the moral hazard hypothesis is true with regard to relief pitching, the coefficient $\beta_{3}$ will be statistically greater than 0 , or the incidence rate ratio will be statistically greater than 1 , representing that an additional relief pitcher in the NL increases the expected number of hit batsmen more than an additional relief pitcher in the AL.

Similarly, the difference between the coefficient on $G R_{g}$ in equation (2) versus (3) is $\beta_{5}$, which represents the additional effect of a game remaining in the NL on the number of hit batsmen. ${ }^{8}$ So, if the moral hazard hypothesis is true with regard to games remaining, the coefficient $\beta_{5}$ will be statistically less than 0 , or the incidence rate ratio will be statistically less than 1, representing that an additional game remaining in the NL decreases the expected number of hit batsmen more than an additional game in the $\mathrm{AL}$.

Table 1 displays summary statistics for all the variables used in the regression analysis.

[Table 1 about here.]

\section{Results}

Table 2 displays the Poisson regression estimates for the sample of all MLB games between 1973 and 2008. ${ }^{9}$ Note that since each game consists of two teams, each game also accounts for two observations, for a total of 155,712 observations. Incidence rate ratios are reported for ease 
of interpretation and consistency with Bradbury and Drinen (2006). The model specifications also follow the approach used in Bradbury and Drinen. The results for the batter quality, pitcher quality, retaliation, and game specific variables are mostly consistent with Bradbury and Drinen (2006), so we again direct the reader to that paper for a discussion of those variables.

[Table 2 here]

Referring to the incident rate ratio on the Designated Hitter variable, Bradbury and Drinen (2006) find a nearly $8 \%$ increase in the likelihood of a hit batsman due to the $\mathrm{DH}$ rule. The results in Table 2 suggest that the DH effect may actually be larger, between $11 \%$ and $18 \%$ when relief pitchers and games remaining are included in the specification.

Consistent with the moral hazard hypothesis, the incidence rate ratio on $N L \times$ Relief Pitchers is statistically greater than 1 . Referring to column (1), the results for the coefficients on Relief Pitchers and $N L \times$ Relief Pitchers imply that an additional relief pitcher in the AL increases the number of hit batsmen by about $15 \%$, whereas an additional relief pitcher in the NL increases the number of hit batsmen by about $18 \%{ }^{10}$ There are several explanations for why the effect of an additional relief pitcher increases the number of hit batsmen, such as the number of relief pitchers being correlated with more opposition at-bats in a game (resulting in more hit batters) and style and control differences between starters and relievers. However, the $3 \%$ difference between leagues is not attributable to these factors and is thus most likely explained as being moral hazard. Alternative specifications suggest similar results.

Figure 2 displays this result graphically, showing the impact of the number of relief pitchers used in the AL versus the NL on the expected number of hit batsmen. The results in Figure 2 were calculated using the Poisson regression shown in Column (1) of Table 2. Figure 2 shows that as the number of relief pitchers used in a game increases, the difference in the 
expected number of hit batsmen per game decreases between the AL and NL. Furthermore, when about 5 relief pitchers are used in a game, the expected number of hit batsmen is about the same for the two leagues. Again, the rationale behind this is that the more relief pitchers used in the NL, the less likely those pitchers bat and face retaliation. Correspondingly, the more those pitchers behave like AL pitchers.

[Figure 2 here]

While statistically different from 1, the incident rate ratios on Games Remaining and NL $\times$ Games Remaining are economically small. The results suggest that the impact of an additional game remaining in the AL increases the number of hit batsmen by only about $0.7 \%$.

Furthermore, in the NL, the impact of an additional game remaining increases the number of hit batsmen by about $0.2 \% .^{11}$ As expected and consistent with the moral hazard hypothesis, the impact of an additional game remaining in the NL is smaller than in the AL. Unexpectedly however, the more games remaining between two teams, the more batters are hit. One possible explanation is that the Games Remaining variable is associated with what point in the season a team is at, such that a game early in the season may not be as important as a game later in the season when teams are competing for a playoff spot. Therefore, pitchers may view games earlier in the season as "lower cost" games which results in more hit batsmen. Nonetheless, the magnitude of the impact is almost trivial.

[Figure 3 here.]

[Figure 4 here.]

\section{Conclusion}

This paper uses game-level data to examine forms of moral hazard in MLB not previously considered. Specifically, this paper looks at whether the number of relief pitchers used and the 
number of games remaining have a moral hazard aspect to them. The results for the relief pitching variables support the moral hazard hypothesis in that the effect of an additional relief pitcher in the NL is larger than the effect of an additional relief pitcher in the AL. Also, an additional game remaining in the NL has less of a positive effect on hit batsmen than an additional game remaining in the AL. However, the effect of an additional game remaining is very small in either league. In general, these results support the moral hazard in baseball hypothesis.

This paper also sheds new light on the debate about why the difference in hit batsmen between the AL and the NL has decreased in more recent years. Past research has debated the reason for the diminishing difference in hit batsmen between the AL and the NL. From 1973 to 1993 AL teams consistently hit more batters per game than NL teams. Not only did AL teams hit more batters, but the size of the difference was quite large. However, from 1994 to 2009 the difference seemingly disappeared. Past research suggests the MLB expansion in $1993^{12}$ and the double warning rule in $1994^{13}$ as possible explanations, however the results in this paper suggest another possible reason for the decrease in the difference of hit batsmen between leagues: the increased use of relief pitching. Over the course of the DH era, the number of relief pitchers used in a game has increased. As Figure 3 shows, the average number of relief pitchers used per game has roughly doubled in both the AL and NL since the beginning of the DH era. This increased use of relief pitching has most likely increased the number of hit batsmen in both the AL and the NL due to "style" differences between starters and relievers, but it has also likely increased the number of hit batsmen in the NL due to moral hazard in relief pitching. Figure 4 shows the actual percent difference in hit batsmen between leagues as compared to the predicted difference in hit batsmen per league if we only allowed the mean number of relief pitchers to 
vary by league. While the percentage difference between the two series fluctuates across years—sometimes considerably—a rough back-of-the-envelope calculation places the percentage of the difference explained at approximately $20 \%$, as the mean predicted difference is $3.14 \%$ over the sample and the mean average difference is $13.91 \%$. Nonetheless, as is evident in Figure 4, as more relief pitchers are used, the possibility of pitchers being retaliated against in either league becomes smaller, thereby eliminating the observed difference between the two leagues. 


\section{References}

Bradbury, J. and D. Drinen. 2006. "The Designated Hitter, Moral Hazard, and Hit Batters: New Evidence from Game-Level Data.” Journal of Sports Economics, 7(3): 319-329.

Bradbury, J. and D. Drinen. 2007. “Crime and Punishment in Major League Baseball: The Case of the Designated Hitter and Hit Batters.” Economic Inquiry, 45(1): 131-144.

Goff, B., W. Shughart, and R. Tollison. 1997. "Batter Up! Moral Hazard and the Effects of the Designated Hitter Rule on Hit Batsmen.” Economic Inquiry, 35(3): 555-561.

Goff, B., W. Shughart, and R. Tollison. 1998. "Moral Hazard and the Effects of the Designated Hitter Rule Revisited.” Economic Inquiry, 36(4): 688-692.

Kawaura, A. 2010. Designated Hitter Rule Debate: A Search for Mr. Hyde in Pitchers. Journal of Sports Economics, 11(3): 349-357.

Kawaura, A. and S. Croix. 2007. "The Designated Hitter Rule and Team Defensive Strategy in Japan’s Professional Baseball Leagues.” Journal of Sports Economics, 8(5): 491-504.

Levitt, Steven, D., 1998. "The Hazards of Moral Hazard: Comment on Goff, Shughart, and Tollison.” Economic Inquiry, 36(4): 685-687.

Major League Baseball Official Rules, 2008. www.mlb.com/mlb/downloads/y2008/official_rules/08_the_pitcher.pdf (accessed November 25, 2009).

Retrosheet, Inc.2009. www.retrosheet.org (Accessed September 15, 2009).

Sports Reference, LLC. 2009. www.baseball-reference.com (Accessed October $14^{\text {th }}, 2009$ ).

Stephenson, F. 2004. “A New Test for Moral Hazard and Hit Batsmen.” Atlantic Economic Journal, 32(4): 360 .

Trandel, G. 2004. "Hit by Pitches: Moral Hazard, Cost-Benefit Retaliation, or Lack of Evidence?” Journal of Sports Economics, 5(1): 87-92. 
Trandel, G., L. White, and P. Klein. 1998. "The Effect of the Designated Hitter Rule on Hit Batsmen: Pitcher's Moral Hazard or the Team's Cost-benefit Calculation? A Comment." Economic Inquiry, 36 (4): 679-684. 


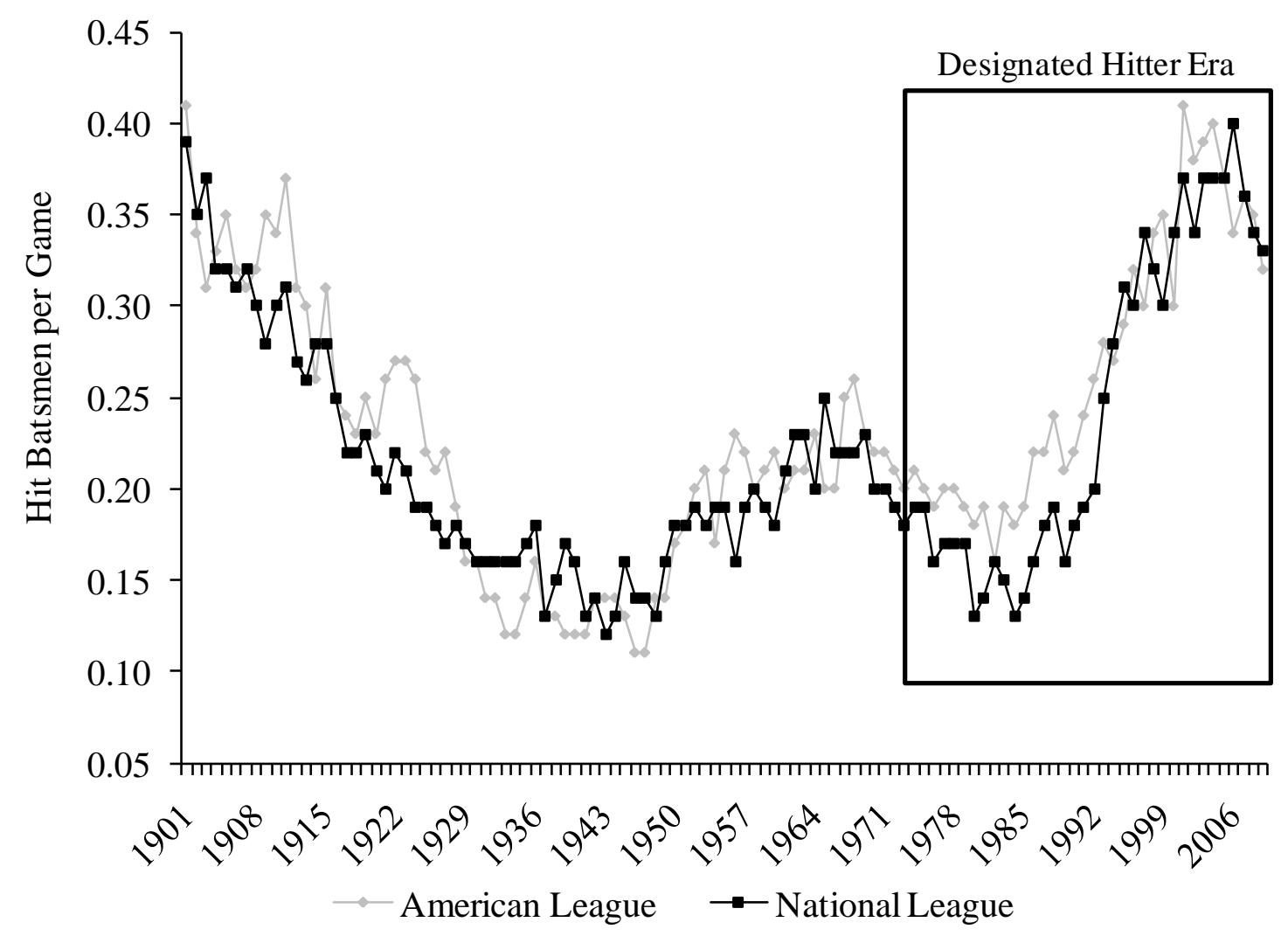

Figure 1: Hit Batsmen Rates by League, 1901 - 2009 
Table 1: Summary Statis tics by League

\begin{tabular}{c|cc|cc|cc|cc}
\hline \multirow{2}{*}{ Variable } & \multicolumn{2}{|c|}{ Mean } & \multicolumn{2}{c|}{ St. Dev. } & \multicolumn{2}{c|}{ Minimum } & \multicolumn{2}{c}{ Maximum } \\
& AL & NL & AL & NL & AL & NL & AL & NL \\
\hline Hit Batsmen & 0.268 & 0.253 & 0.534 & 0.524 & 0.000 & 0.000 & 5.000 & 5.000 \\
\hline Designated Hitter & \multicolumn{2}{|c|}{0.505} & \multicolumn{2}{|c|}{0.500} & \multicolumn{2}{c|}{0.000} & \multicolumn{2}{c}{1.000} \\
\hline NL & \multicolumn{2}{|c|}{0.495} & \multicolumn{2}{|c|}{0.500} & 0.000 & \multicolumn{2}{c|}{1.000} \\
\hline Relief Pitchers & 1.972 & 2.281 & 1.314 & 1.387 & 0.000 & 0.000 & 10.000 & 10.000 \\
\hline Games Remaining & 6.678 & 7.084 & 4.083 & 4.597 & 1.000 & 1.000 & 20.000 & 19.000 \\
\hline Runs Scored per Game & 4.582 & 4.323 & 0.609 & 0.569 & 2.031 & 2.148 & 6.228 & 6.228 \\
\hline Runs Allowed per Game & 4.650 & 4.398 & 0.551 & 0.548 & 3.210 & 3.010 & 6.810 & 6.350 \\
\hline Walks Allowed per Game & 3.335 & 3.316 & 0.435 & 0.391 & 2.148 & 2.148 & 4.839 & 4.549 \\
\hline Batters Hit & 0.268 & 0.253 & 0.534 & 0.523 & 0.000 & 0.000 & 5.000 & 5.000 \\
\hline Home Runs & 0.953 & 0.872 & 1.042 & 0.995 & 0.000 & 0.000 & 10.000 & 9.000 \\
\hline Runs Ahead and/or Behind & 0.000 & 0.000 & 4.380 & 4.106 & -27.00 & -22.00 & 27.00 & 22.00 \\
\hline Absolute Score & 3.478 & 3.252 & 2.663 & 2.506 & 0.000 & 0.000 & 27.00 & 22.00 \\
\hline
\end{tabular}

Note: Since Designated Hitter is always a 1 when a game is played under AL rules and a 0 when played under NL rules and $N L$ is always a 0 when a game is played under AL rules and 1 when played under NL rules, summary statistics for these two variables are from the entire dataset, instead of separated by league. 
Table 2: Determinants of Hit Batters, 1973-2008

\begin{tabular}{|c|c|c|c|c|c|}
\hline $\begin{array}{l}\text { Dependent Variable: Hit } \\
\text { Batsmen }\end{array}$ & (1) & (2) & (3) & (4) & (5) \\
\hline Variable & IRR & IRR & IRR & IRR & IRR \\
\hline Designated Hitter & $\begin{array}{c}1.133 * * * \\
(0.031) \\
\end{array}$ & $\begin{array}{c}1.117 * * * \\
(0.030) \\
\end{array}$ & $\begin{array}{c}1.117 * * * \\
(0.030) \\
\end{array}$ & $\begin{array}{c}1.162 * * * \\
(0.031) \\
\end{array}$ & $\begin{array}{c}1.177 * * * \\
(0.031) \\
\end{array}$ \\
\hline Relief Pitchers & $\begin{array}{c}1.150 * * * \\
(0.006) \\
\end{array}$ & $\begin{array}{c}1.180 * * * \\
(0.006) \\
\end{array}$ & $\begin{array}{l}1.18 * * * \\
(0.006)\end{array}$ & $\begin{array}{c}1.183 * * * \\
(0.006)\end{array}$ & $\begin{array}{c}1.184 * * * \\
(0.006)\end{array}$ \\
\hline$N L \times$ Relief Pitchers & $\begin{array}{c}1.026^{* * * *} \\
(0.007)\end{array}$ & $\begin{array}{c}1.023^{* * * *} \\
(0.007)\end{array}$ & $\begin{array}{c}1.023 * * * \\
(0.007)\end{array}$ & $\begin{array}{c}1.025^{* * *} \\
(0.007) \\
\end{array}$ & $\begin{array}{c}1.024 * * * \\
(0.007) \\
\end{array}$ \\
\hline Games Remaining & $\begin{array}{c}1.007 * * * \\
(0.002) \\
\end{array}$ & $\begin{array}{c}1.007 * * * \\
(0.002) \\
\end{array}$ & $\begin{array}{c}1.007 * * * \\
(0.002) \\
\end{array}$ & $\begin{array}{c}1.007 * * * \\
(0.002) \\
\end{array}$ & $\begin{array}{c}1.007 * * * \\
(0.002) \\
\end{array}$ \\
\hline$N L \times$ Games Remaining & $\begin{array}{l}0.995 * * \\
(0.002) \\
\end{array}$ & $\begin{array}{l}0.995 * * \\
(0.002) \\
\end{array}$ & $\begin{array}{c}0.995 * * \\
(0.002) \\
\end{array}$ & $\begin{array}{l}0.995^{* *} \\
(0.002) \\
\end{array}$ & $\begin{array}{l}0.994 * * \\
(0.002) \\
\end{array}$ \\
\hline Runs Scored per Game & $\begin{array}{c}1.015 \\
(0.012) \\
\end{array}$ & $\begin{array}{c}1.043 * * * \\
(0.013) \\
\end{array}$ & $\begin{array}{c}1.045^{* * * *} \\
(0.012) \\
\end{array}$ & $\begin{array}{c}1.052 * * * \\
(0.012) \\
\end{array}$ & $\begin{array}{l}- \\
- \\
\end{array}$ \\
\hline Runs Allowed per Game & $\begin{array}{c}1.117 * * * \\
(0.012) \\
\end{array}$ & $\begin{array}{c}1.154 * * * \\
(0.012) \\
\end{array}$ & $\begin{array}{c}1.154 * * * \\
(0.012) \\
\end{array}$ & $\begin{array}{l}- \\
-\end{array}$ & $\begin{array}{l}- \\
- \\
\end{array}$ \\
\hline $\begin{array}{c}\text { Walks Allowed Per } \\
\text { Game }\end{array}$ & $\begin{array}{c}1.011 \\
(0.013) \\
\end{array}$ & $\begin{array}{c}0.986 \\
(0.013) \\
\end{array}$ & - & - & $\begin{array}{l}- \\
- \\
\end{array}$ \\
\hline Batters Hit & $\begin{array}{c}1.111 * * * \\
(0.010) \\
\end{array}$ & $\begin{array}{c}1.075^{* * * *} \\
(0.009) \\
\end{array}$ & - & - & - \\
\hline Home Runs & $\begin{array}{c}0.950 * * * \\
(0.005) \\
\end{array}$ & - & - & - & - \\
\hline $\begin{array}{c}\text { Runs Ahead and/or } \\
\text { Behind }\end{array}$ & $\begin{array}{c}1.040 * * * \\
(0.001) \\
\end{array}$ & $\begin{array}{l}- \\
-\end{array}$ & $\begin{array}{l}- \\
-\end{array}$ & $\begin{array}{l}- \\
-\end{array}$ & $\begin{array}{l}- \\
-\end{array}$ \\
\hline Absolute Score & $\begin{array}{c}1.017 * * * \\
(0.002)\end{array}$ & - & - & - & - \\
\hline
\end{tabular}

Note: Incidence rate ratios with robust standard errors are in parentheses. Constants and year dummies not reported. Each regression includes two observations for every game played in MLB between 1973 and 2008 , for a total of 155,712 observations. ${ }^{*}$ p-value $<0.10, * *$ p-value $<.05$, $* * *$ p-value $<.01$. 


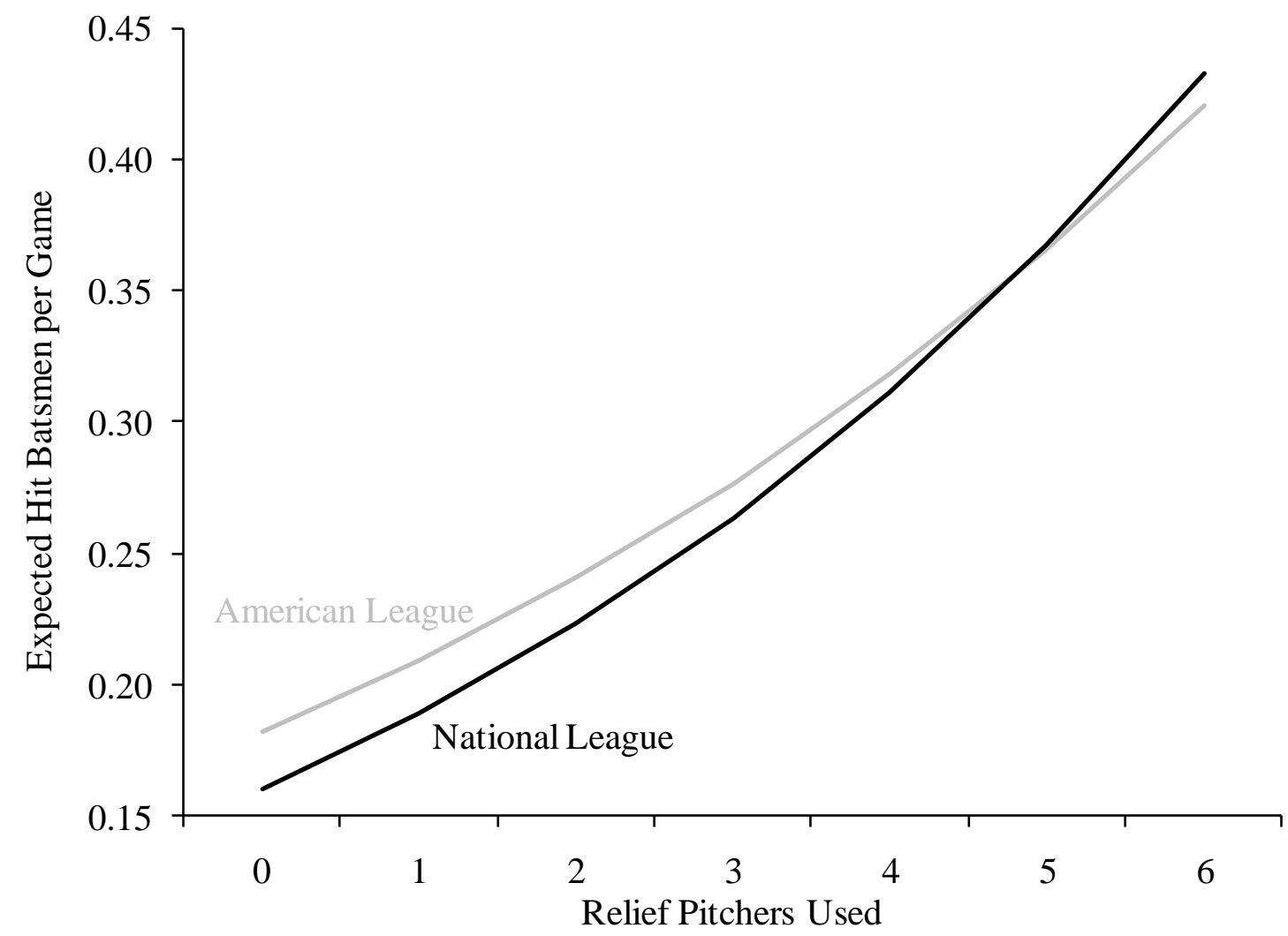

Figure 2: Expected Hit Batsmen and Relief Pitchers used per game 


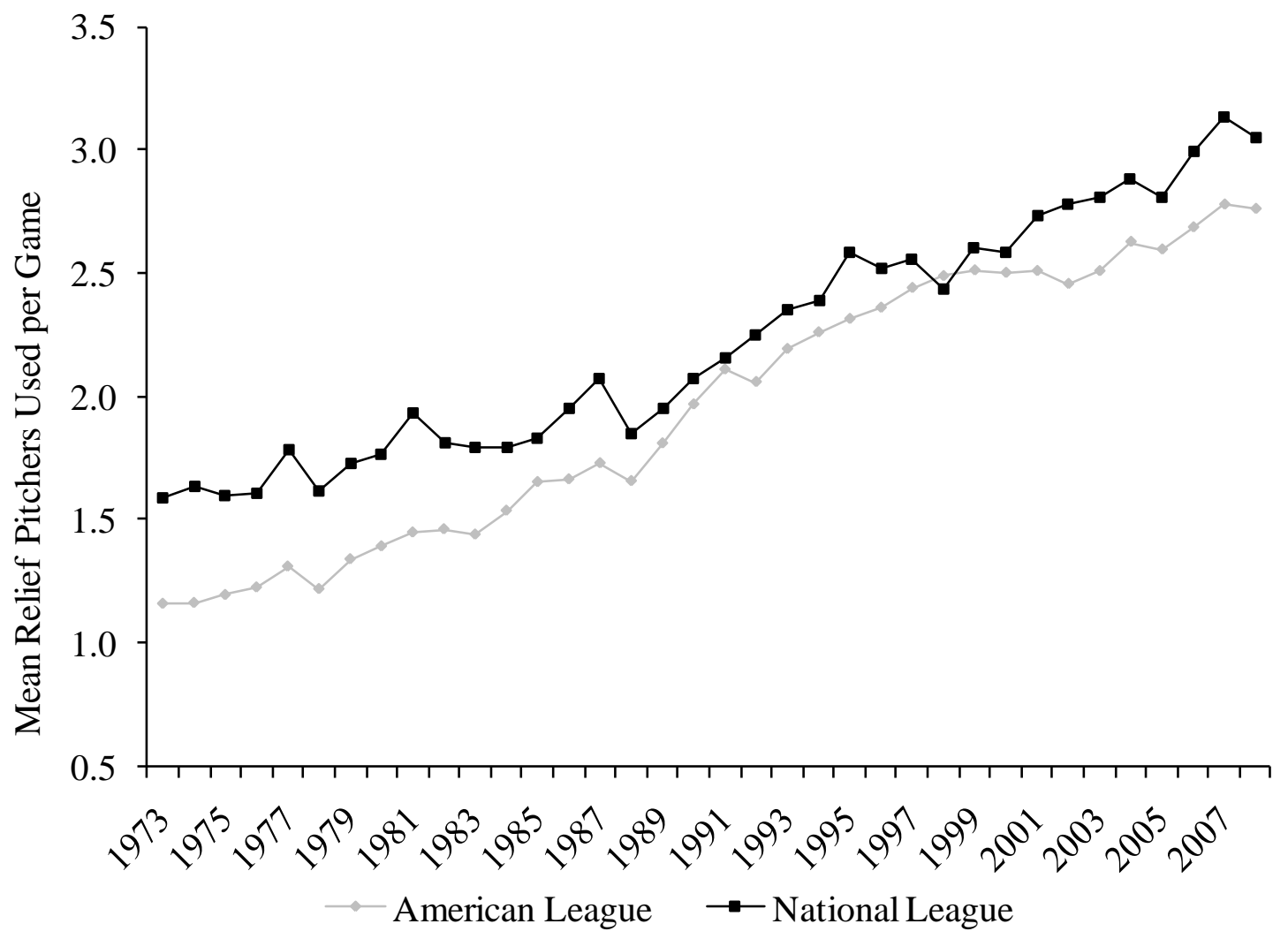

Figure 3: Mean Relief Pitchers used per Game by League, 1973 - 2008 


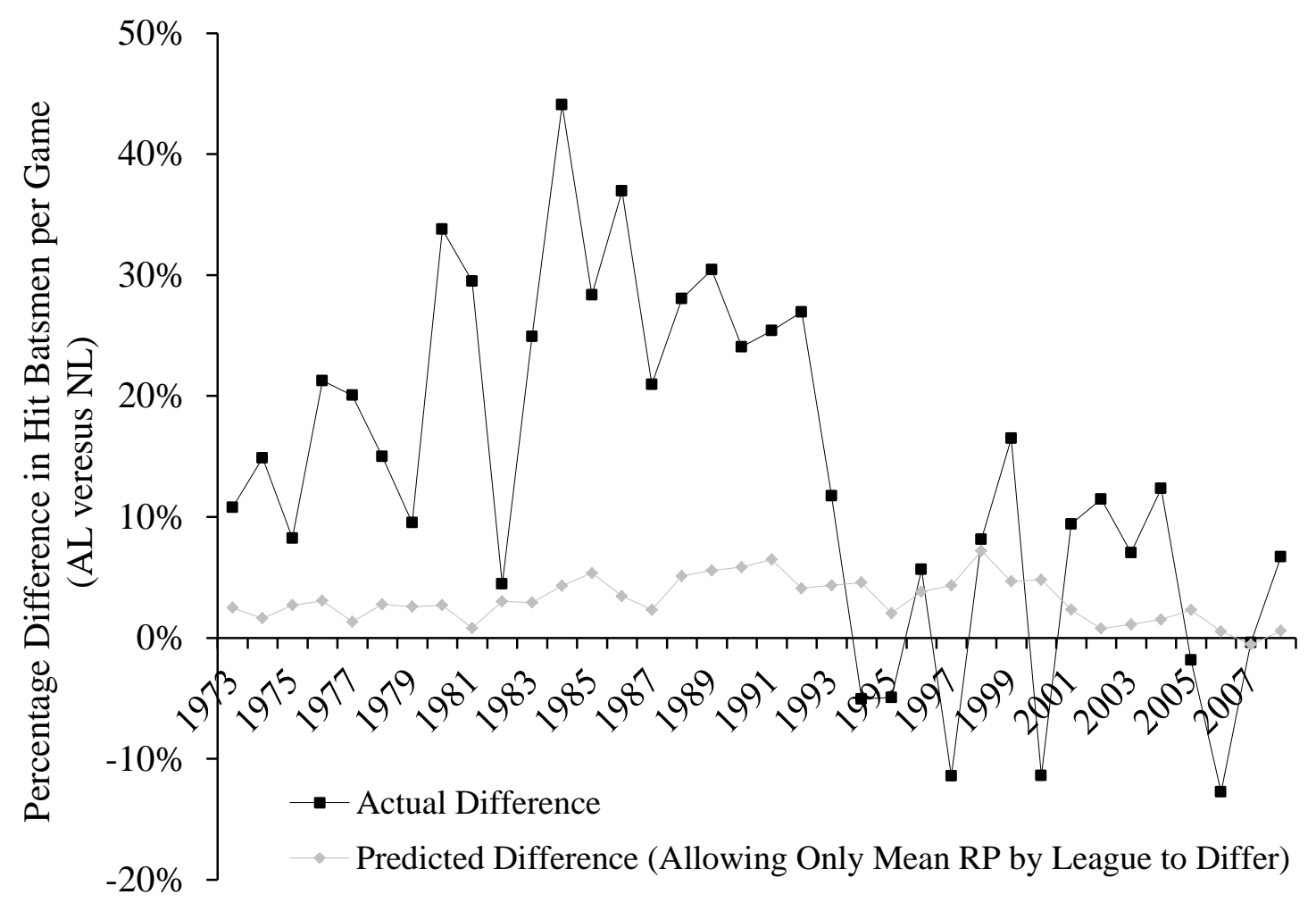

Figure 4: Percentage Differences (AL versus NL) in Hit Batsmen per Game, 1973 - 2008

\section{Endnotes}

${ }^{1}$ This rule was introduced in MLB in 1973. Games played under a DH rule dictate that teams have the choice to replace one of their fielders at the beginning of the game with a DH on offense. As pitchers are generally the weakest hitters, teams choose to replace their pitchers and, as such, the pitchers do not bat. 
${ }^{2}$ For instance, as of 2009, career NL reliever Trevor Hoffman has appeared in 978 games but only batted 33 times. By comparison, career NL starter Greg Maddux has appeared in 744 games and has batted 1,591 times. Furthermore, Trevor Hoffman has never been hit by a pitch in his career, while Maddux has been hit 5 times.

${ }^{3}$ We clearly assume that retaliation does not spillover from one season to the next. As previous studies (as well as ours) control for year fixed effects, this assumption best matches with the existing research and with our empirical framework.

${ }^{4}$ The information used here was obtained free of charge from Retrosheet and is copyrighted by Retrosheet. Interested parties may contact Retrosheet at www.retrosheet.org.

${ }^{5}$ The variable $N L_{g}$ is just the opposite of $D H_{g}$, so when $D H_{g}$ is equal to 1 for an observation, $N L_{g}$ is equal to 0 , and vice versa. While it would be sufficient to merely use ${ }^{2} H_{g}$ in the interaction terms, we believe that this form allows for easier interpretation and explanation.

${ }^{6}$ Note that the argument here is not that a NL reliever hits more batters than an AL reliever, but that an NL reliever hits more batters than an NL starter. It is the switching from starter (who bats) to reliever (who rarely bats) that accounts for the additional effect of a reliever in the NL.

${ }^{7}$ The coefficient $\beta_{2}$ represents the effect of an additional relief pitcher in the $\mathrm{AL}$ on the number of hit batsmen. This is expected to be positive, since relief pitchers generally pitch more recklessly than starting pitchers and tend to rely less on control. Regardless, the sign and magnitude of $\beta_{2}$ alone is not particularly relevant to the moral hazard problem which is the focus here.

${ }^{8}$ The coefficient $\beta_{4}$ represents the effect of an additional game remaining in the AL on the number of hit batsmen. This is expected to be 0 , since the number of games remaining in the AL should not directly affect the number of batters the pitching team hits. Again, as in the previous case, the sign and magnitude of $\beta_{4}$ alone is not particularly relevant to the moral hazard problem which is the focus here.

${ }^{9}$ As in Bradbury and Drinen (2006), similar estimates are obtained, but not reported, using the negative binomial regression to account for the possibility of overdispersion. Negative binomial regression results are nearly identical to the Poisson regression results presented here. These estimates are available upon request.

${ }^{10}$ Note that the incident rate ratios in the Poisson regression are calculated by taking the exponential of the coefficient estimates. Since the exponential function is non-linear, it is not accurate to simply add together the incidence rate ratios to find the aggregated effect. Instead the coefficient estimates should be added together and then the exponential of that taken. That is how the $18 \%$ here is calculated. In column (1) of Table 2 the coefficient estimates on Relief Pitchers and NL $\times$ Relief Pitchers are 0.139762 and 0.025668 respectively. So the combined coefficient for the $N L$ is 0.16543 . Thus the incidence rate ratio for the effect of Relief Pitchers in the NL is $\exp (0.16543)=1.1799$.

${ }^{11}$ See endnote 10 regarding this calculation. In column (1) of Table 2 the coefficient estimates on Games Remaining and $N L \times$ Games Remaining are 0.006976 and -0.00501 respectively. So the combined coefficient for the $N L$ is 0.001963 . Thus the incidence rate ratio for the effect of Games Remaining in the NL is $\exp (0.001963)=$ 1.001965 .

${ }^{12}$ The expansion added two additional teams to the NL. Thus, past researchers have suggested the expansion allowed for newer pitchers who were less talented to enter the NL. Being less talented, these pitchers hit more batters, or so the argument goes.

${ }^{13}$ Official Rule 8.02 (d), the double warning rule stipulates that if the umpire deems a pitch to be intentionally thrown at a batter then he can warn both teams that another pitch of the same kind will result in the ejection of the 
pitcher and the manager. Correspondingly, the first warning by an umpire prevents pitchers from using retaliation, thus eliminating the moral hazard problem, or so the argument goes. 